\title{
Hanging on by a thread: gastric extraction of ingested tampons
}

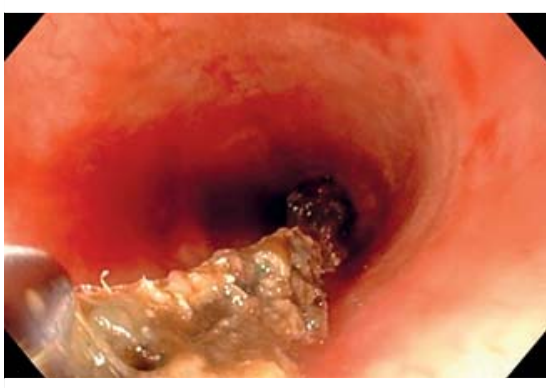

- Fig. 1 Endoscopic view showing a tampon being extracted by grasping its cord.

A 24-year-old patient with a history of psychiatric co-morbidity presented after auto-ingestion of tampons and batteries. Both had been ingested on several occasions in the preceding 24 hours, and the patient declined to specify an exact number of ingested foreign bodies.

While we were able to easily extract the batteries with a snare, the extraction of the tampons presented a challenge. A single guideline [1] mentions tampon ingestion, but does not elaborate the endoscopic technique required for effective extraction. The tampons were swollen with gastric secretions and were too wide to be passed through an overtube, while a Roth net basket was too small to fully grasp the tampon. A snare provided excellent grip when grasping the tampon in its middle, but this transverse alignment of the tampon made it too wide to pass through the gastroesophageal junction (GEJ). The use of a snare or Rockstar basket to grasp the side of a tampon provided insufficient grip to pull the tampon across the GEJ. Finally, capture of the tampon cord allowed both an effective grip and the necessary longitudinal alignment with the GEJ for successful extraction ( $\triangleright$ Fig. 1; Video 1), and allowed the extraction of 15 tampons, along with seven batteries ( $\mathbf{F i g} \mathbf{2}$ ).

To the best of our knowledge, this is the first report describing gastric extraction of ingested tampons, and we believe that the method presented here pro-

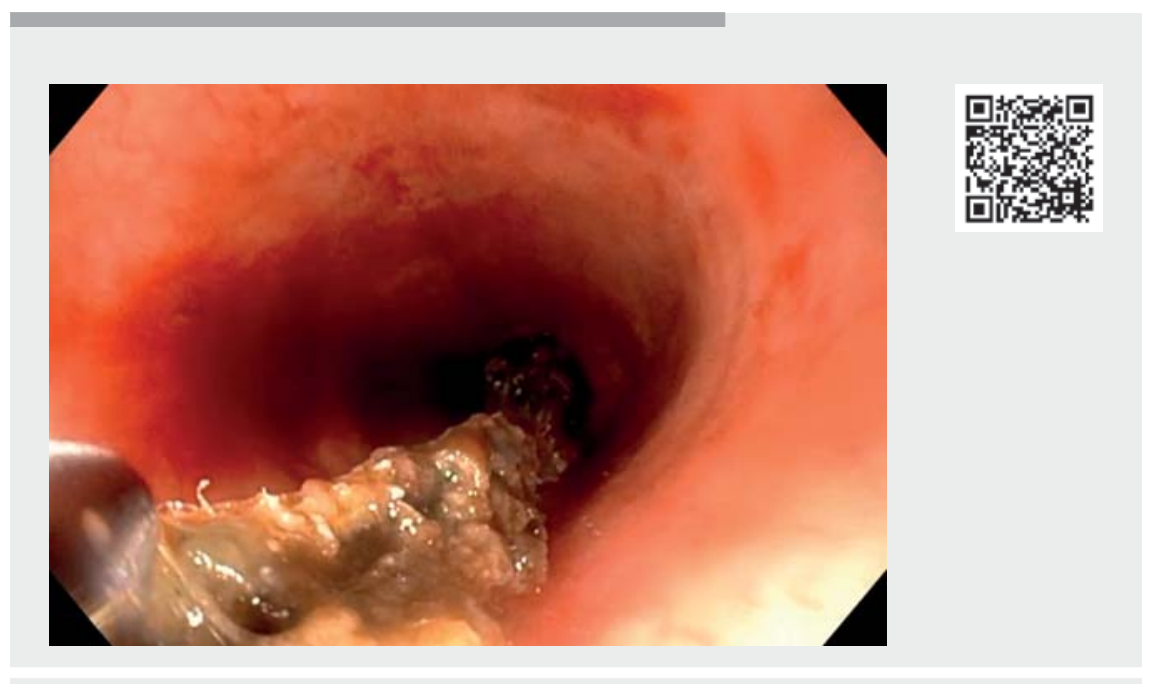

$\square$ Video 1 Gastric extraction of multiple ingested tampons.

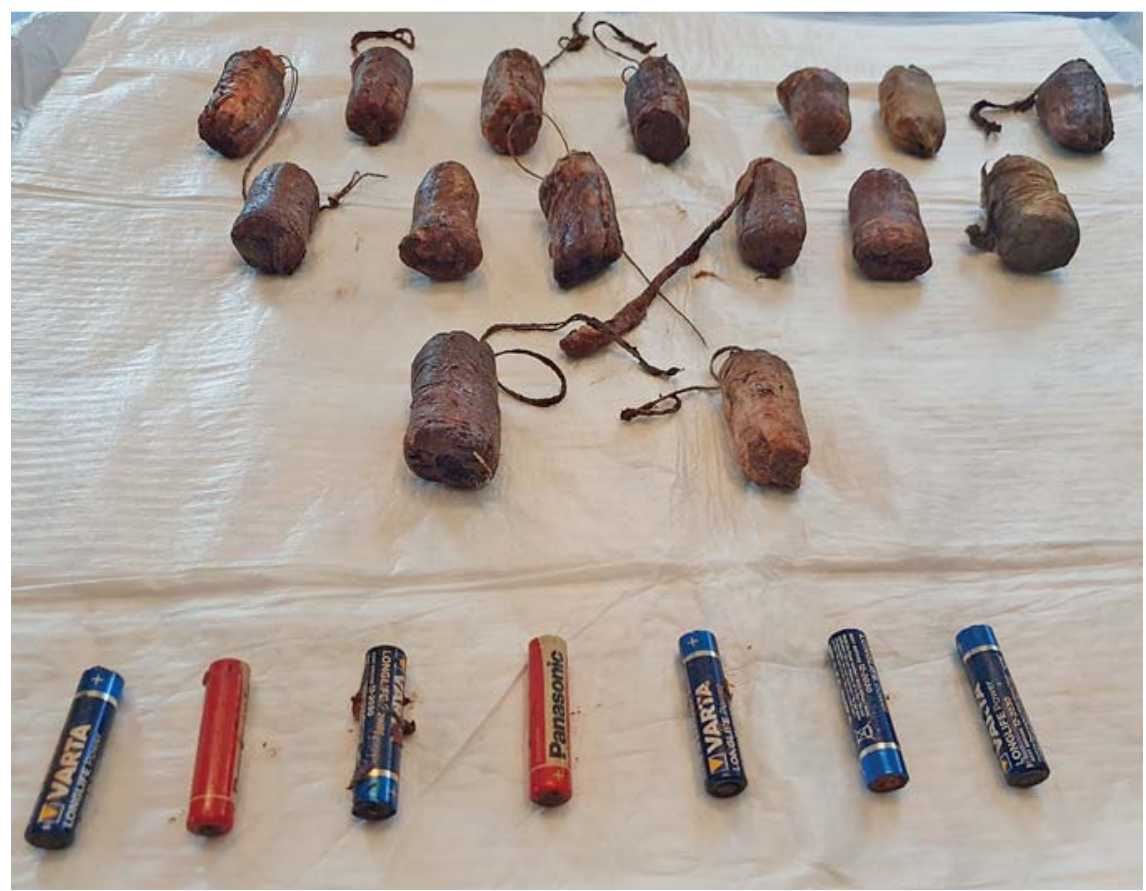

Fig. 2 Photograph of the extracted foreign bodies.

vides an effective way of extracting such challenging objects from the upper gastrointestinal tract.

Endoscopy_UCTN_Code_TTT_1AO_2AL

\section{Competing interests}

The authors declare that they have no conflict of interest. 
Kirill Basiliya, Henk-Marijn de Jonge, Koen van Hee

Department of Gastroenterology and Hepatology, Jeroen Bosch Hospital,

's-Hertogenbosch, The Netherlands

Corresponding author

Kirill Basiliya, MD, PhD

Department of Gastroenterology and Hepatology, Jeroen Bosch Hospital, Henri Dunantstraat 1, 5223 GZ 's-Hertogenbosch, The Netherlands

kirill.v.basiliya@gmail.com
[1] Sahn B, Mamula P, Ford CA. Review of foreign body ingestion and esophageal food impaction management in adolescents. J Adolesc Health 2014; 55: 260-266

Bibliography

Endoscopy 2022; 54: E178-E179

DOI 10.1055/a-1463-1971

ISSN 0013-726X

published online 28.4.2021

(c) 2021. Thieme. All rights reserved.

Georg Thieme Verlag KG, Rüdigerstraße 14, 70469 Stuttgart, Germany
ENDOSCOPY E-VIDEOS

https:/|eref.thieme.de/e-videos

口回 Endoscopy E-Videos is an

open access online section, 回和: reporting on interesting cases and new techniques in gastroenterological endoscopy. All papers include a high quality video and all contributions are freely accessible online. Processing charges apply (currently EUR 375), discounts and wavers acc. to HINARI are available.

This section has its own submission website at

https://mc.manuscriptcentral.com/e-videos 